\title{
México en la mirada anglosajona: buscando al Humboldt integral
}

\author{
A propósito de Juan A. Ortega y Medina, Obras (vols. 3 y 4), México, \\ UNAM, 2015, 578 pp. (vol. 3), 345 pp. (vol. 4). \\ Rodolfo GuTIÉRREZ SiMÓN \\ Universidad Complutense de Madrid \\ rodolfo.gutierrez@ucm.es
}

Exponer en unas cuantas páginas el pensamiento de Juan A. Ortega y Medina, cuyas Obras están reuniendo y editando sus discípulas María Cristina González y Alicia Mayer, resulta una tarea indudablemente complicada. La dificultad es de triple raíz: primero, por la apasionante y trágica vida del propio autor, recogida hermosamente en la biografía que la ya citada María Cristina González llevase a cabo bajo el título Juan A. Ortega y Medina. Entre Andrenios y Robinsones ${ }^{1}$, que bien merecería que nos detuviéramos largo rato; en segundo lugar, por la cantidad de razones que debieran enumerarse en pos de sacar del inmerecido anonimato en que se encuentra al académico; y tercero, por la vastedad y complejidad de una obra que, aunque cristalina, requeriría un largo estudio que le hiciera justicia.

Sobre la biografía de Juan A. Ortega y Medina daré sólo los datos más fundamentales. Nacido en Málaga en 1913, y fallecido en México en 1992, encarna de manera plena aquél término que Gaos acuñase para sus compañeros exiliados: transterrados. Antes de su afincamiento forzoso en México, Ortega cursó algunos años en la Universidad Central de Madrid y, desatada la guerra, tomó parte en la misma por el bando republicano, resultando gravemente herido (se aleja nuestro protagonista, pues, del tipo de soldado que fuera Nietzsche, con mi mayor respeto por los camilleros). Por fortuna, como he indicado, su vida en México fue -forzado me hallo a resumir en demasía- feliz y fructuosa, desempeñando cargos académicos reconocidamente premiados. No puedo dejar de advertir que se naturalizó mexicano, agradecido a su tierra de acogida, aunque nunca dejó de sentirse español.

Cuatro son los volúmenes de sus obras que ya han visto la luz: Europa moderna, Evangelización y destino, Literatura viajera y Humboldt. De los dos primeros ya he

\footnotetext{
${ }^{1}$ México, Instituto Nacional de Historia y Antropología, 2005. Infinitamente más resumida, y casi como prólogo a un catálogo de las obras del autor, puede verse también el texto de E. Meyer, Espíritu y vida en claro. El quehacer histórico de Juan A. Ortega y Medina, México DF, UNAM, 2007.
} 
dado debida noticia en otro lugar ${ }^{2}$, y allí remito a quien quiera ver un poco más por extenso los temas que en esos dos tomos se trabajan y sus fuentes (principalmente, weberianas); sin embargo, la obra de nuestro protagonista está tan perfectamente trabada que es inexcusable que retome algunas cuestiones ya tratadas para dar mayor claridad a las nuevas.

Si hubiera que destacar dos preocupaciones centrales, estas serían la evangelización puritana en Norteamérica y la doctrina del llamado "destino manifiesto". Sin embargo, es evidente que tras tan amplia temática hay multitud de puntualizaciones que hacer. Por ello, trataré de recorrer de manera general los volúmenes que hasta ahora han sido publicados.

Comencemos repasando los dos primeros tomos. Ya en la que fuera su tesis de maestría, Reforma y modernidad, podemos apreciar la importancia que Ortega y Medina concede al movimiento protestante para la configuración del mundo moderno. Dicho así, parece que su avance es algo menor: a todos se nos ha enseñado en la escuela la relevancia de Lutero y Calvino para el devenir de la historia europea. Sin embargo, en este caso nos encontramos frente a un punto de partida, no de llegada. Así, en el que quizá sea el segundo libro más importante de don Juan Antonio, El conflicto anglo-español por el domino oceánico. Siglos XVI y XVII apreciamos un despliegue de ideas que resultarán más que interesantes. De manera ciertamente paralela a Max Weber, Ortega aprecia cómo la doctrina protestante determina el modo de vida y la concepción del mundo de sus devotos, y cómo dicho modo de vida y dicha concepción del mundo difieren notoriamente de los que tienen o llevan consigo los católicos españoles. Para ilustrarlo, recurrirá hábilmente Ortega al contraste entre dos personajes literarios (tendencia muy de agradecer en su obra: el recurso tanto a obras históricas como literarias y artísticas); recurre, como digo, a dos personajes paradigmáticos de ambas culturas: el Robinson inglés y el Andrenio del Criticón. Estos dos tipos humanos encuentran su correlato en el proceder de sus respectivas monarquías y, más interesante para nosotros, en el modo en que se desarrollaron la concepción del mar y la conquista-explotación de las tierras ultramarinas. Dicho de manera muy resumida, Ortega y Medina aprecia una clara relación entre protestantismo (en este caso, principalmente anglicano, aunque estos matices ahora no han de detenernos) y empresa privada; y la relación especular entre catolicismo y monopolismo eclesiástico-monárquico ${ }^{3}$. Dado el carácter todoterreno de nuestro autor, nos encontraremos frente a análisis de todo tipo, incluyendo una cierta historia de la guerra que pone de manifiesto la flexibilidad inglesa frente a la petrificada visión

\footnotetext{
${ }^{2}$ R. Gutiérrez Simón, "De Andrenios y Robinsones: crítica de una leyenda (negra)", en Res Publica. Revista de Historia de las Ideas Políticas 18, Núm. 2, 2015, pp. 469-485.

${ }^{3}$ Aunque de pasada, esta tesis reaparece en el estudio introductorio que Ortega y Medina elaboró para el libro de Humboldt Ensayo político sobre el reino de la Nueva España, lo que patentiza la unidad de su pensamiento (cf. Obras 4, p. 230).
} 
hispánica (aquel "mantenella e no emendalla" encontraría su traducción bélico-naval en una negativa felipina a innovar en el arte de la guerra, con fatales resultados).

La centralidad del modo de vida adherido a cada tipo de religiosidad es también el punto de partida del, ahora sí, más importante libro del autor: La evangelización puritana en Norteamérica, contenido en el tomo 2 de estas Obras. En él se lleva a cabo la descripción de cómo los novoingleses fueron variando su visión de lo que América y los indios eran, desde el asombro inicial y la concepción del "buen salvaje" a la conquista más despiadada. Así, señalará nuestro autor, el protestantismo calvinista-ascético sería, permítaseme decirlo así, la excusa para el adueñamiento de la tierra y el exterminio del indio. Ortega no dejará pasar la oportunidad de deshacer la famosa leyenda negra española: la evangelización franciscana en la Nueva España incorporaba al indio a la sociedad (en mejores o peores condiciones); la evangelización puritana, en cambio, implicaba la obligación moral-religiosa de adueñarse de una tierra infrautilizada y el desprecio a unos aborígenes predestinadamente condenados y diabólicos. Claro está que aquí me veo forzado a resumir; no puedo dejar de recomendar que se lea con detenimiento una obra cuya importancia está aún por ser reconocida. Les estoy invitando, ahí es nada, a ser pioneros en el conocimiento de un autor que está a un paso de un Olimpo que le abre las puertas con retraso.

Unida a todo lo que vengo contando está la otra gran preocupación que antes mencionaba: la tesis del destino manifiesto. Nuestro buen historiador detecta en los ingleses, como antes se encontrara en los judíos, un cierto sentimiento de pueblo elegido que, por medio de la singular evangelización en Norteamérica, se contagiará a la sociedad estadounidense. Así, en Destino manifiesto. Sus razones históricas y su raiz teológica vemos desarrollada esta idea y podemos intuir algo, por cierto, evidente: que hoy ese sentimiento sigue ahí. Para alguien que vivía en México, la cuestión adquirió una gravedad superlativa, máxime en una época de conflicto entre los dos lados del tristemente célebre muro berlinés.

Aunque no se sale de estos dos temas, el tercer tomo de las Obras (cuyo título, no se olvide, es Literatura viajera) aborda estos mismos problemas desde una diferente perspectiva. Así, el grueso de este volumen está destinado a analizar la visión que los viajeros anglosajones (ingleses, estadounidenses y, en menor medida, alemanes) tuvieron de México. Tal es el objeto de estudio de México en la conciencia anglosajona. Este libro aparece por primera vez como unidad: antes circularon por separado sus dos partes, destinada la primera a los siglos XVI, XVII y, en menor medida, XVIII (no estaba entonces el horno para viajes); y la segunda parte, al siglo XIX, específicamente al periodo comprendido entre 1821 y 1847 . Tanto en unos como en otros se encuentra una huella constante: México, pese a su espíritu claramente republicano, tenía un lastre evidente por su herencia hispánica. Su hispano-catolicismo, pues, hacía que el país resultase siempre imperfecto para quien lo miraba con monóculos protestantes, aunque Ortega y Medina acierta, en numerosas ocasiones, a ver más allá: la mayoría de viajeros fueron torciendo su gesto según se les vaciaba la bolsa y 
se le frustraban las expectativas de negocio (minería, fundamentalmente). Así, continúa la unidad temática con los dos tomos anteriores y permitirá entroncarlo con el tomo cuarto, dedicado a Humboldt, aquel viajero que determinará de modo radical la visión que los anglosajones decimonónicos tendrían sobre México. Quiero destacar que en esta obra (México en la conciencia anglosajona) encontramos ciertos pasajes que muestran no sólo el buen hacer de Ortega y Medina como historiador, sino también su calidad literaria y su sensibilidad estética: las líneas que dedica a la guitarra y su sensualidad, o la atención que presta al momento en que se oyen campanas llamando a misa desde una plaza de toros abarrotada, son pura delicia hasta para quienes no ven reflejada su españolidad en el coso taurino ${ }^{4}$.

De manera nítidamente imperfecta he expuesto algunas ideas vertebradoras de los libros recogidos en estas obras. Sin embargo, todos los volúmenes incluyen un buen puñado de artículos (algunos forman un libro en sí mismo, como Imagología del bueno y del mal salvaje). En general, todos complementan los grandes textos a los que he aludido, y no puedo por tanto detenerme en ellos. Sin embargo, creo que debo al menos mencionar el título de los más significativos: "Lutero y su contribución a la modernidad" y "De Andrenios y Robinsones", en el primer volumen; y "Razones y sinrazones anglosajonas frente al otro" en el segundo. Respecto al tercer tomo, que nos ha de interesar más en esta nota, son notorios, por lo menos, tres artículos $^{5}$. En primer lugar, quiero destacar el texto más humilde de cuantos han salido hasta ahora: el "Informe del viaje del doctor Juan A. Ortega y Medina", donde se ve su ansia investigadora, su candidez y su buen hacer; segundo, el que quizá sea más interesante de todos, "Monroísmo arqueológico. Un intento de compensación de americanidad insuficiente". Este texto (que ha de leerse en relación con otro, a mi juicio, menos relevante, pero aclarador: "La manipulación historiográfica estadounidense del pasado histórico y arqueológico latinoamericano") es increíblemente luminoso, y por ello voy a dedicarle algunas palabras más.

No hace falta mucho tiempo para resumir el artículo, pero ello no resta un ápice a su importancia. Ortega toma como punto de partida la insuficiente americanidad norteamericana; esto es, el sentimiento de los propios estadounidenses de no ser, pese a su poderío, sino una copia de Europa en América ${ }^{7}$; y, en tanto que copia, devalua-

\footnotetext{
${ }^{4}$ Ortega advierte muy hábilmente que también la tauromaquia es empleada por los viajeros anglosajones para vilipendiar el hispánico origen del pueblo mexicano; por ejemplo, en Obras 3, p. 174. ${ }^{5}$ Además de los tres que voy a destacar en el cuerpo del texto, encontramos los siguientes: "Pródromos de la escalada viajera anglosajona", "Estudio preliminar a Seis meses de residencia y viajes en México", "México a raíz de la Independencia", "Contumelia maledicti", "México en 1830", "México en 1832", "México en 1841", "La correspondencia de Hugo Finck, 1862" y "La manipulación historiográfica estadounidense del pasado histórico y arqueológico latinoamericano".

${ }^{6}$ Obras 3, pp.541-557.

${ }^{7}$ No me parece que sea exagerado vincular esta idea con la de otro Ortega, en este caso, José Ortega y Gasset; explícitamente dice éste en La rebelión de las masas (aunque refiriéndose específicamente al
} 
ción. Ante esta falta de americanidad, la salida fue la apropiación (unilateral) por su parte del arte maya, que reunía las condiciones de ser antiguo (pudiendo competir con el arte griego por ser "clásico") y propiamente americano. Esta adquisición del arte maya, de sus restos materiales, está justificada a partir de la obra del explorador y viajero John Lloyd Stephens, quien, viendo la magnificencia de las ruinas mayas, se siente heredero de dicho arte como un artista europeo se sentía receptor del arte universal. Se quiebran así el problema geográfico y el racismo protestante (no era un arte criollo, pues los criollos lo habían ignorado ${ }^{8}$ e, incluso, vendido por baratijas, esto es, lo habían despreciado; ni era un arte propio de salvajes, dada su majestuosidad). Creo que estamos ante una buena muestra del valor de la obra de Ortega y Medina.

El tercer artículo que me gustaría destacar del tercer tomo lleva por título "La literatura viajera alemana del siglo XIX sobre México". En él se aprecia que esta presencia también tuvo lugar y, de hecho, tuvo menos prejuicios anti-católicos y anti-hispánicos a la hora de juzgar el país? Sin embargo, esto no implica que la visión germánica sobre el país azteca estuviera exenta de todo sesgo. En este caso, el prejuicio tiene nombre y apellidos: Alexander von Humboldt. Tal es la importancia del geógrafo, explorador, pensador y tantas otras cosas más para Ortega y Medina que a él va dedicado el cuarto volumen, precisamente llamado Humboldt. Es el momento de entrar en él.

Más de la mitad de este cuarto tomo (el más breve de los publicados hasta ahora, pero no por ello el menos denso) lo compone un libro de profundo interés historiográfico: Humboldt desde México. Lo que en él se propone su autor es llevar a cabo una tarea hercúlea, a saber: analizar buena parte de las obras mexicanas (o realizadas en México, por decirlo más precisamente) referidas a los textos humboldtianos. Para ello, establece una primera división formal, que parte explícitamente el libro: por un lado, el siglo xIx; por otro, el xx. Sería absurdo que tratase de enumerar aquí los autores, textos, prólogos, discursos e incluso artículos periodísticos que Ortega tomó en consideración para la elaboración de su libro; baste decir que el abanico es enorme, incluyendo a autores semidesconocidos y a grandes estrellas como, por ejemplo, Alfonso Reyes o Edmundo O'Gorman.

Más allá de esa distinción entre siglos, el libro se articula en torno a las distintas fechas que pudieron emplearse como efeméride relativa al paso del ilustre viajero por México (centenario de su muerte, de su obra, etc.), cronológicamente ordenadas. Esto permite ver fácilmente lo que el autor quiere mostrar: la trayectoria de la recepción de Humboldt.

siglo XIX) que "América está hecha con el reboso de Europa" (J. Ortega y Gasset, Obras Completas. Tomo IV, Madrid, Taurus, 2004-2010, p. 402).

${ }^{8} \mathrm{Ha}$ de constar que también algunos visitantes hicieron tal cosa. Así, sobre Becher nos dice Ortega que "es uno de los pocos viajeros que no se dedicó a recorrer las ruinas prehispánicas, pues parece que tenía ya firmemente arraigados sus prejuicios" ("México en 1832", en Obras 3, p. 423).

${ }^{9}$ Cf. Obras 3, p. 319. 
En un principio, esta tarea -al margen de la minería de datos que supone- no parece destinada a cotas demasiado elevadas: pudiera parecer que es sólo un collage en que se recopilan informaciones. Pero no es eso ni lo más importante, ni lo que el autor se propone. Lo que las páginas del texto ponen clarísimamente de manifiesto es la visión parcial y, más grave aún, sumamente interesada que se ha hecho de Humboldt en la tierra mexicana. La visión es parcial en tanto en cuanto, durante el siglo XIX, se tendió mucho más a considerar el Ensayo político sobre el reino de la Nueva España que el resto de la obra del autor (en particular, Ortega está pensando en Cosmos); con el transcurrir de los años, fue decayendo también el interés por el mismísimo Ensayo.

La causa de esa parcialidad es, precisamente, el otro punto que he destacado siguiendo a Ortega: el interés. Si en el siglo XIX se consideró particularmente relevante la visión humboldtiana de México fue porque era una profunda invitación para los inversionistas europeos. Convenía, pues, a los dirigentes mexicanos "vender" el producto, y a los alemanes explotar tierras tan fecundas...en teoría. Ya he dicho más arriba que la visión optimista sobre el país fue tornándose más oscura exactamente en la misma proporción en que las monedas iban siendo desalojadas de las carteras.

Por supuesto, la utilización de Humboldt fue también considerada por Ortega y Medina en términos políticos. En este sentido, se demora debidamente en el uso del porfirismo para una potenciación de su máximo representante, arropado por la sombra del sabio prusiano y respaldado por la representación alemana en el país -cuyos intereses crematísticos y geoestratégicos han sido debidamente marcados. Cabe señalar en este punto un cierto trasfondo antifrancés y progermánico que perfectamente se entiende en el marco de la situación europea del momento.

Humboldt desde México es, como ya he dicho, una perfecta historia de las sucesivas formas de recepción y utilización de la obra de Humboldt en tal lugar de la tierra. Ortega va recorriendo todas las etapas, de entre las que ya he destacado algunas, y a las que habría que añadir -en clara relación con el porfiriato--, el positivismo. Sin embargo, dada la claridad del texto, me gustaría alejarme de su línea argumental principal para subrayar dos cuestiones sumamente relevantes que no han de pasar desapercibidas, acaso para aumentar la visión de los potenciales lectores sobre el libro. En primer lugar, el denodado interés de Ortega y Medina por poner a Humboldt en su lugar. Esto supone, por una parte, desmitificar al pensador. Como era de esperar, criticar al ídolo de tantos y tantos escritores, historiadores y mexicanistas le llevó a ciertas polémicas de las que, a mi modo de ver, salió airoso (buen ejemplo es su texto "Otra vez Humboldt, ese controvertido personaje", contenido en este volumen $4^{10}$, y en el que se despacha a gusto frente a la injusta crítica que Jaime Labastida vertió contra el prólogo que nuestro autor realizó al Ensayo).

\footnotetext{
$\overline{{ }^{10} \text { Concretamente, pp. }}$ 275-300.
} 
¿En qué sentido debemos entender esta crítica, no tanto a Humboldt, como al "Humboldt mexicano", o a su recepción en México? Desde mi punto de vista, en el más sano. Lo que en último término Ortega y Median pretende hacer es, como ya he señalado, poner a Humboldt en su lugar. Esta tarea requiere dar dos pasos. En primer lugar, y en favor del pensador alemán, poner en valor el conjunto de su obra" ${ }^{11}$-tristemente maltratado en favor del Ensayo por los intereses explicitados. Pero, en segundo lugar, supone valorizar lo que había en México antes de que Humboldt llegara. El propio sabio ya reconoció que muchos de los datos que luego magistralmente organizó procedían de la labor científica que muchos mexicanos habían llevado a cabo y gentilmente le habían cedido. Tal afirmación - vista hoy, tan evidente- suponía reafirmar el valor del México español colonial. He aquí la gravedad del asunto: si Humboldt daba alas al independentismo mexicano, Ortega y Medina tuvo a bien señalar que no todo lo que los españoles llevaron desde la metrópolis ni o que hicieron allá fue tan negativo: de nuevo nuestro autor, como frente a la leyenda negra, se convierte en un deshacedor de mitos injuriosos. En este sentido, no deja de ser significativo un hecho que, al margen de estas consideraciones, pudiera parecer baladí: el motto del libro es una cita de la Historia de la filosofía en México de Samuel Ramos; y es bien sabido que éste postuló, de manera polémica pero penetrante, la necesidad mexicana de reconocer su herencia hispana ${ }^{12}$, aunque a los propios mexicanos no les gustase la idea $^{13}$.

Unos párrafos más arriba he dicho que quería destacar dos elementos subyacentes a la obra Humboldt desde México. El primero, que se pretendía poner a Humboldt en su lugar, ha quedado (así lo espero) suficientemente claro. El segundo no requiere tanta explicación: Ortega y Medina señala en varias ocasiones -prueba de que no es una afirmación pasajera- el liberalismo de Humboldt, filiando su doctrina a la de Adam Smith ${ }^{14}$. Creo que reincidir en ello yo también permitirá entender de forma aún más apropiada la visión que nuestro autor tiene sobre el célebre viajero ${ }^{15}$.

\footnotetext{
${ }^{11}$ Justamente esto es lo que ha sido imposible hasta ahora por el interés concedido al Ensayo; cf. Obras 4, p. 19.

${ }^{12}$ Me refiero, claro está, a la obra El perfil del hombre y la cultura en México. Nótese también esta presencia de la teoría de Ramos en México en la conciencia anglosajona, cuando señala Ortega y Medina que si algo libró a las colonias españolas de los intentos de conquista anglosajones, fue »el feroz e indomable individualismo heredado de España» (Obras 3, p. 113; el subrayado es mío), si bien en otro momento de la misma obra añade que "los latidos de la sangre mestiza, que hoy por hoy se polarizan en los extremos de lo indio y lo español, tendrán que ser espaciados para dar cabida justiciera en ellos al aporte espiritual y sanguíneo de lo negro" (p. 43).

${ }^{13}$ Sobre el intento del México independiente por mostrarse inicialmente al mundo como antiespañola, cf. "Pródromos de la escalada viajera anglosajona", en Obras 3, p. 261.

${ }^{14}$ Esto queda explicitado en el "Estudio introductorio al Ensayo político sobre el reino de la Nueva España", en Obras 4, p. 229.

${ }^{15}$ No está de más que recuerde un hecho, de nuevo, aparentemente intrascendente, pero que considero muy interesante, a saber: que John Stuart Mill coloque como motto del tratado clásico por excelencia
} 
Para ir cerrando esta nota, debo apuntar que el volumen cuarto incorpora de nuevo una serie de artículos y textos varios que dan cohesión y profundidad al libro central. Al más interesante ya me he referido: el estudio introductorio realizado para el Ensayo de Humboldt. Lo más interesante de éste no es tanto la maravillosa introducción que supone, sino el hecho de que Ortega lee el libro como debe hacerse: desde su propio presente. Esto no significa descontextualizar los contenidos de la obra -incide en que Humboldt debe entenderse desde Humboldt-. La aparente paradoja entre las dos últimas afirmaciones, sin embargo, se resuelve fácilmente: al leer una obra cualquiera, en este caso el Ensayo, hay que realizar un desdoblamiento. Así, por una parte, se ha de ver lo que el texto y su autor quisieron decir en sus propios términos y desde su perspectiva; por otra, se ha de pensar lo que eso supone para mí como lector, lo que ya se ha superado y lo que aún permanece vigente -esto último, la vigencia de lo que nos plantea, es el elemento diferenciador entre un autor al uso y un clásico. En el caso de la lectura orteguiana de Humboldt, lo decisivo es que hay un rasgo del México decimonónico que se mantiene en la segunda mitad del siglo $\mathrm{xx}$ : la desigualdad ${ }^{16}$.

Los otros textos que componen el volumen, aunque a mi modo de ver son menos impactantes, tienen también su interés. Si "El Humboldt de José Miranda" pormenoriza la visión sobre el autor que más interesó a Ortega y Medina, "Otra vez Humboldt, ese controvertido personaje" nos permite ver, como ya he señalado, la desenvoltura de nuestro protagonista en las polémicas.

Cierran el tomo dos artículos que han de leerse sucesivamente. Así, Ortega y Medina dice que cabe considerar la obra de un autor de dos modos: centrándose en una obra específica, o tratando de atender a la totalidad de su corpus. Y justamente ambas lecturas son las que ensaya: en "El Ensayo cubano de Alejandro de Humboldt desde la perspectiva historiográfica mexicana" pone el punto de mira, claro está, en el Ensayo político sobre la isla de Cuba; en "Landeskunde humboldtiana y pintura del paisaje" se centra en la visión total del autor, poniendo de manifiesto que existe "una directa relación entre las descripciones poético-pictóricas de Humboldt y los cuadros de la escuela paisajista mexicana, particularmente la del representante sin par de toda ella, el pintor José María Velasco" ${ }^{17}$.

Pasado el ecuador de la publicación de estas Obras de Juan A. Ortega y Medina, sólo queda esperar los próximos tres volúmenes: Historiografía y teoría de la historia, Descubrimiento y conquista y Temas y problemas de historia, que serán indudablemente de gran interés investigador y de accesible prosa para el lector casual.

en favor del liberalismo, Sobre la libertad, una cita de Esfera y deberes del gobierno, de Wilhelm von Humboldt, hermano de Alexander.

${ }^{16}$ Cf. Obras 4, p. 274.

${ }^{17}$ Obras 4, p. 336. 